\title{
KIDUNG RUMEKSA ING WENGI KARYA SUNAN KALIJAGA DALAM KAJIAN TEOLOGIS
}

\author{
M. Sakdullah \\ Mahasiswa Pascasarjana Universitas Islam Negeri (UIN) \\ Walisongo Semarang \\ e-mail: sakdullah14@yahoo.co.id
}

\begin{abstract}
Kidung Rumeksa Ing Wengi that written by Sunan Kalijaga, one of Walisongo members (the nine saints) at Java. In this Kidung, Sunan Kalijaga discussed on the danger of night which came from genie (jin), satan, and man. To ward off the danger, he advocated Muslims to read it at night. For this reason, for Moslem Javanese especially, this Kidung is recognized the most sacral and they always read it every night to get the protection from God.
\end{abstract}

\begin{abstract}
Abstrak: artikel ini bertujuan mengeksplorasi Kidung Rumeksa Ing Wengi yang ditulis oleh Sunan Kalijaga, salah satu anggota dari Walisongo (sembilan wali) di Jawa. Dalam Kidung ini, Sunan Kalijaga membahas tentang bahaya malam hari yang berasal dari jin, setan, dan manusia. Untuk menangkal bahaya tersebut, ia menganjurkan umat Islam untuk membacanya pada malam hari. Untuk alasan ini, bagi Muslim Jawa khususnya, Kidung ini sangat sakral dan mereka selalu membacanya setiap malam untuk memperoleh perlindungan dari Tuhan.
\end{abstract}

Keywords: Sunan Kalijaga, Sunan Bonang, Ahlu alSunnah wa al-Jamā’ah, Tuhan, manusia.

\section{A. Pendahuluan}

Sebelum masuknya Islam di tanah Jawa, masyarakat Jawa tidak mengalami kekosongan masalah kebudayaan melainkan berbagai 
M. SAKDULLAH: Kidung Rumeksa Ing Wengi

kebudayaan berpengaruh telah berakar kuat dalam kehidupan mereka. ${ }^{1}$ Islam datang dengan dua pendekatan utama yang paling substansial tentang bagaimana cara yang ditempuh agar nilai-nilai Islam diserap menjadi bagian dari budaya Jawa. Pendekatan yang pertama disebut dengan Islamisasi kultur Jawa, yaitu sebuah pendekatan yang diupayakan agartampak bercorak Islam, baik secara formal maupun substansial. Upaya ini ditandai dengan cara penggunakan istilah-istilah Islam, nama-nama Islam, pengambilan peran tokoh Islam pada berbagai cerita lama, sampai kepada penerapan hukum-hukum atau norma-norma Islam dalam berbagai aspek kehidupan. Adapun pendekatan yang kedua disebut Jawanisasi Islam yang diartikan sebagai upaya pengintegralisasian nilai-nilai Islam melalui cara penyusupan ke dalam budaya Jawa. Istilah-istilah dan nama-nama Jawa tetap dipakai, tetapi nilai-nilai yang dikandungnya adalah nilai-nilai Islam, sehingga Islam menjadi menJawa. Berbagai kenyataan menunjukkan bahwa produk-produk budaya orang Jawa yang beragama Islam cenderung mengarah kepada polarisasi Islam ke Jawa yang ke-Islaman sehingga timbul istilah Islam Jawa atau Islam Kejawen. ${ }^{2}$

Kalangan ulama Nusantara pada waktu itu memang telah berhasil mengintegrasikan antara ke-Islaman dengan ke-Indonesiaan lebih khusus lagi pada masyarakat Jawa yang telah terealisasikan oleh para walisongo, sehingga apa yang ada di daerah Jawa telah dianggap sesuai dengan nilai Islam karena Islam menyangkut nilainilai dan norma, bukan hanya yang berkaitan dengan ideologi Arab saja melainkan pengambilan inti dari ajaran Islam tersebut yang dimasukkan dalam budaya Jawa. ${ }^{3}$

Ketika nilai Islam dianggap sesuai dengan adat setempat, maka adat tidak perlu lagi diubah sesuai ideologi Arab, sebab bila itu dilakukan akan menimbulkan kegoncangan budaya. Misalnya, pada awal mula penyebaran agama Islam salah satu anggota Walisongo, Sunan Bonang melakukan langkah penyebaran agama Islam di tanah 
Jawa dengan tidak mempertimbangkan proses asimilasi dan akulturasi dengan adat dan kepercayaan setempat yang menimbulkan kegoncangan budaya. ${ }^{4}$ Berbeda dengan anggota Walisongo lainnya, Sunan Kalijaga yang menyebarkan Islam melalui tradisi yang ada pada masyarakat waktu itu. Selain pakaian adat, Sunan Kalijaga juga mengarang cerita-cerita wayang yang telah disesuaikan dengan nafas ke-Islaman yang santun dan lunak sehingga dapat diterima masyarakat Jawa, yang pada waktu itu masih sangat kuat memegang kepercayaan Hindu dan Budha. ${ }^{5}$ Salah satu karyanya, Kidung Rumeksa Ing Wengi, adalah bukti bagaimana Sunan Kalijaga menyampaikan ajaran Islam dengan menggunakan istilah-istilah yang mudah dipahami oleh masyarakat Jawa saat itu. ${ }^{6}$ Untuk mengetahui lebih jauh pemikiran Sunan Kalijaga dalam Kidung Rumeksa Ing Wengi, artikel ini hanya menganalisis aspek teologis dari kidung tersebut.

\section{B. Sunan Kalijaga dan Kidung Rumeksa Ing Wengi}

Bukti sejarah keberadaan Sunan Kalijaga dapat dilihat dari makamnya yang terletak di tengah kompleks pemakaman Desa Kadilangu yang dilingkari dinding dengan pintu gerbang makam. Area makam Sunan Kalijaga masih di dalam kota Demak kira-kira berjarak sekitar $3 \mathrm{~km}$ dari Masjid Agung Demak. Seperti makam Walisongo pada umumnya, makam Sunan Kalijaga berada di dalam bangunan tungkub berdinding tembok dengan hiasan dinding terbuat dari kayu jati berukir.Nama asli Sunan Kalijaga adalah Raden Sahid, putra Tumenggung Wilatika, Bupati Tuban.Ia juga dikenal dengan beberapa nama: Syaikh Melaya, Lokajaya, Raden Abdurrahman, Pangeran Tuban, dan Ki Dalang Sida Brangti. Namanama ini memiliki kaitan erat dengan sejarah perjalanan hidup sang wali. $^{7}$

Hasanu Simon telah mencoba menemukan tanggal kelahiran Sunan Kalijaga dari berbagai sumber.Ia mengutip Majalah Gatra yang 
M. SAKDULLAH: Kidung Rumeksa Ing Wengi

menerangkan bahwa Sunan Kalijaga diperkirakan lahir tahun 1430an. Dugaan ini dihitung dari perkawinan Raden Sahid dengan Siti Khafsah, putri Sunan Ampel. Pada waktu itu usiaRaden Sahid diperkirakan sekitar 20 tahun, sedang usia Sunan Ampel sekitar 50 tahun. Namun, jika dikaitkan dengan pembangunan masjid Demak pada decade 1460-an, tampaknya yang benar kelahiran Raden Sahid adalah sekitar tahun 1440-an. Kalau ditinjau dari peranannya dalam pengangkatan Mas Karebet menjadi Sultan Pajang pada tahun 1564, maka usia Sunan Kalijaga sudah terlalu tua, yaitu lebih dari 120 tahun. Dari sudut ini, menurut Hasanu Simon, kelahiran Sunan Kalijaga adalah sekitar tahun 1450, yang berarti pada tahun 1564 berusia sekitar 110 tahun, suatu usia yang matang untuk menjadi penentu dalam keputusan politik negara. ${ }^{8}$

Menurut Babad Tuban, kakek Sunan Kalijaga yang bernama Aria Teja, nama aslinya adalah Abdurrahman, orang keturunan Arab. Karena berhasil mengislamkan Adipati Tuban yang bernama Aria Dikara, Abdurrahman mengawini putri Aria Dikara. Ketika menggantikan kedudukan mertuanya sebagai Bupati Tuban, Abdurrahman menggunakan nama Aria Teja. Dari perkawinan dengan putri Aria Dikara ini, Aria Teja memiliki putra bernama Aria Wilatikta.Sebelum menikah dengan putri Aria Dikara, Aria Teja telah menikah dengan putri Raja Surabaya yang bernama Aria Lembu Sura. Dari pernikahan itu, Aria Teja memiliki seorang putri yang dikenal dengan nama Nyai Ageng Manila yang kelak diperistri Sunan Ampel. ${ }^{9}$ Sejalan dengan Babad Tuban, C.L.N. Van Den Berg dalam Le Hadhramaut et les Colonies dans l'Archipel Indien, menyatakan bahwa Sunan Kalijaga adalah keturunan Arab. Van Berg memaparkan garis silsilah Sunan Kalijaga sebagai berikut:

Abdul Muthalib berputra Abbas, berputra Abdul Wakhid, berputra Mudzakir, berputra Abdullah, berputra Kharmia, berputra Mubarak, berputra Abdullah, berputra Madhra'uf, berputra Arifin, berputra Hasanuddin, berputra Jamal, berputra Ahmad, berputra Abdullah, berputra Abbas, berputra Kourames, 
berputra Abdurrahman (Aria Teja, Bupati Tuban), berputra Teja Laku (Bupati Majapahit), berputra Lembu Kusuma (Bupati Tuban), berputra Tumenggung Wilatikta (Bupati Tuban), berputra Raden Sahid (Sunan Kalijaga). ${ }^{10}$

Guru agama utama Sunan Kalijaga adalah Sunan Bonang.Dari Sunan Bonang ini, Sunan Kalijaga tidak hanya belajar Islam, melainkan juga belajar seni dan kebudayaan Jawa yang membuatnya memahami dan menguasai kesusastraan Jawa beserta pengetahuan falak dan pranatamangsa. ${ }^{11}$ Sedangkan Islam yang diajarkan oleh Sunan Bonang adalah Ahlu as-Sunnah wa al-Jamā'ah. Menurut Widji Saksono, Walisongo itu sejiwa, yaitu jiwa Islam; seideologi dan sealiran, yaitu tasawuf dan mistik; dan sejalan pikiran, yaitu jalan pikiran Ahlu as-Sunnah wa al-Jamā'ah. ${ }^{12}$ Mazhab ini, di samping mengutamakan soal-soal batin, seperti tasawuf, mistik, dan akhlak, juga tidak melalaikan soal-soal lahir seperti syariat. ${ }^{13}$

Bukti kepiawaian Sunan Kalijaga dalam sastra terlihat dari beberapa hasil karyanya, antara lain,Serat Dewaruci, kitab Suluk Linglung, dan Kidung Rumekso Ing Wengi. Jika dibaca sekilas, antara Serat Dewaruci dan Suluk Linglung isinya sama, tetapi ada perbedaan yang mempunyai arti sangat penting. Di dalam Serat Dewaruci tidak disinggung masalah syariat, sedangkan di dalam Suluk Linglung dengan tandas Sunan Kalijaga menekankan perlunya bagi orang Islam untuk melaksanakan salat dan puasa Ramadan dengan tertib dan sungguh-sungguh seperti yang dicontohkan oleh Rasulullah. Serat Dewaruci ditulis lebih dulu, ketika Sunan Kalijaga masih muda, sedangkan Suluk Linglung ditulis kemudian. ${ }^{14}$

Dalam Kidung Rumeksa Ing Wengi-nya, Sunan Kalijaga cenderung pragmatis, ${ }^{15}$ uraian-uraian yang disampaikannya berkaitan dengan urusan-urusan praktis dalam kehidupan sehari-hari. Kidung ini mempunyai 45 bait tembang yang bermetrum dandhanggula, tetapi yang sering dilantunkan oleh orang Jawa adalah bait pertama sampai bait kelima. ${ }^{16}$ Ditemukan juga di 
M. SAKDULLAH: Kidung Rumeksa Ing Wengi

lapangan, orang Jawa sering membaca Kidung ini dari bait pertama hingga kedelapan. ${ }^{17}$

Dalam Kidung-nya ini Sunan Kalijaga memaparkan bahwa setiap hari manusia tidak bisa terlepas dari istirahat (tidur), khususnya dimalam hari, namun malam merupakan tempat berlindung yang baik bagi perbuatan jahat. Kelemahan di waktu malam ini sangat penting agar besoknya bisa melanjutkan kehidupan di bumi.Iamenawarkan tata cara berdoa keselamatan di malam hari karena keselamatan merupakan bagian pokok dari misi agama. Agama apa saja kurang memiliki makna bagi pemeluknya jika tidak ada keselamatan yang bisa ditawarkan kepada pemeluknya.

Kidung Rumeksa Ing Wengi ditulis oleh Sunan Kalijaga untuk menjembatani hal-hal yang bersifat supranatural.Sebab, pada tahuntahun awal perkembangan Islam di Jawa bersifat sangat mistis yang pada dasarnya merupakan kepercayaan pra-Islam yang masih sangat dipengaruhi oleh paham animisme dan dinamisme.Kenyataan yang terjadi pada saat Sunan Kalijaga menyebarkan Islam adalah serangan dari lawan-lawannya dengan menggunakan ilmu hitam (black magic). Untuk membentengi diri dan para pengikutnya, Sunan Kalijaga menggubah Kidung tersebut yang berisi berbagai macam mantra (doa) untuk menolak balak di malam hari, seperti teluh, tenung, santet, dan lain-lain.

Kidung Rumeksa Ing Wengi merupakan sarana dakwah dalam bentuk tembang yang popular dan menjadi "kidung wingit" karena dipercaya membawa tuah seperti mantra sakti. Dakwah itu dirangkai menjadi sebuah tembang bermetrum Dandhanggula berisi sembilan bait dan seolah-olah sampai saat ini abadi. Orang-orang pedesaan masih banyak yang hafal dan mengamalkan syair kidung ini.Sebagai sarana dakwah kepada anak cucu, nasehat dalam bentuk tembang lebih langgeng dan awet dalam ingatan. Sepeninggal Sunan Kalijaga, Kidung ini menjadi milik rakyat, mereka dengan tulus membaca dan mengamalkannya sebagai doa. ${ }^{18}$ 


\section{Unsur-unsur Teologis dalam Kidung Rumeksa Ing Wengi}

Dalam artikel ini, unsur-unsur teologis dibatasi pada penjelasan tentang Tuhan, manusia, dan relasinya dengan Tuhan. ${ }^{19}$ Dalam Kidung Rumeksa Ing Wengi ini persoalan teologis tersebut dimaksudkan untuk memberikan pedoman bagi masyarakat Jawa dalam menghadapi datangnya zaman edan, kala bendhu ${ }^{20}$ dan kalatidha. ${ }^{21}$

\section{Tuhan}

Iman kepada Allah menjadikan landasan yang kuat bagi kehidupan setiap Muslim untuk mengarungi bahtera kehidupan yang penuh dengan gelombang, mereka tidak bimbang, tidak ragu-ragu menghadapi setiap persoalan yang dihadapinya. Pikirannya cerah, hatinya terang dan tentram, mempunyai pendirian yang kuat serta mempunyai sikap optimis dalam hidup sebagaimana dijelaskan dalam al-Quran: "Yaitu orang-orang yang beriman dan hati mereka menjadi tentram dengan mengingat Allah. Ingatlah Allah hanya dengan mengingat Allah hati menjadi tentram." (QS.al-Ra'd [13]:28).

Allah menurut ajaran Islam, adalah Tuhan Yang Maha Esa. Segala sesuatu mengenai Tuhan disebut ke-Tuhan-an. Iman kepada Allah merupakan dasar-dasar keselamatan manusia menurut alQuran. Tanpa keimanan ini perbuatan manusia menjadi sia-sia. Demikian pula dinyatakan bahwa kekufuran menghapus amal, sebagaimana syirik, ketiadaan iman, pengingkaran terhadap ayatayat Allah dan kehidupan yang berdasarkan kepentingan duniawi semata.

Sedemikian sentralnya posisi teologis dalam Islam, sehingga dengannyalah diukur segala perbuatan manusia, baik dan buruknya. Allah pun memberikan sarana kepada manusia untuk sampai kepada-Nya. Diantaranya adalah ayat-ayat Allah yang ada disekitar manusia. 
M. SAKDULLAH: Kidung Rumeksa Ing Wengi

Gambara teologis Islam dalam Kidung Rumeksa Ing Wengi terdapat tentang Tuhan dalam bait pertama, yaitu:

Ana Kidung rumeksa ing wengi

Teguh hayu luputa ing lara

Luputa bilahi kabeh

Jim setan datan purun

Paneluhan tan ana wani

Miwah panggawe ala

Gunaning wong luput

Geni atemahan tirta

Maling adoh tan ana ngarah mring mami

Guna duduk pan sirna

Ada nyanyian yang menjaga di malam hari

Kukuh selamat terbebas dari penyakit

Terbebas dari semua malapetaka

Jin setan jahat pun tidak ada yang berani

Segala jenis sihir tidak berani

Apalagi perbuatan jahat

Guna-guna pun tersingkir

Api akan menjadi air

Pencuri pun jauh tak ada yang menuju padaku

Guna-guna sakti pun lenyap.22

Dari kata-kata 'Ana Kidung rumeksa ing wengi' (ada nyanyian yang menjaga di malam hari), Sunan Kalijaga ingin mengajak umat Islam saat itu untuk membaca dan mengamalkan sungguh-sungguh Kidung-nya ini demi keselamatan di malam hari. Sebab dengan cara inilah niscaya mereka akan selamat dari berbagai macam kejahatan yang berasal dari jin, setan, dan manusia yang menggunakan ilmu hitam. Mengapa Sunan Kalijaga sangat menekankan pentingnya berjaga-jaga dari kejahatan di malam hari? Boleh jadi ini merupakan pemahaman atau penjelasan Sunan Kalijaga atas surah al-Falaq dan an-Nas, yang masing-masing berbunyi sebagai berikut:

Katakanlah: "Aku berlindung kepada Tuhan yang menguasai subuh; dari kejahatan makhluk-Nya; dan dari kejahatan malam 
apabila telah gelap gulita; dan dari kejahatan wanita-wanita tukang sihir yang menghembus pada buhul-buhul; dan kejahatan orang yang dengki apabila ia dengki” (QS. al-Falaq [113]: 1-5).

Katakanlah: "Aku berlindung kepada Tuhan manusia; Raja manusia; Sembahan manusia; dari kejahatan (bisikan) setan yang biasa bersembunyi; Yang membisikkan (kejahatan) ke dalam dada manusia; dari jin dan manusia" (QS. an-Nas [114]: 1-6).

Pada ayat ke-3 surat al-Falaq disebutkan "dan dari kejahatan malam apabila telah gelap gulita", yang mengisyaratkan bahwa biasanya malam memang menakutkan, karena sering kali kejahatan dirancang dan terjadi dicelah kegelapannya, baik dari para pencuri, perampok, pembunuh, maupun binatang buas, berbisa, atau serangga. ${ }^{23}$ Tentu, malam tidak selalu melahirkan kejahatan. Sebaliknya, bahkan al-Quran memuji malam sebagai saat yang terbaik untuk mendekatkan diri kepada Allah: Sesungguhnya bangun di waktu malam adalah lebih tepat untuk khusyuk dan bacaan di waktu itu lebih berkesan (QS. al-Muzzammil [73]: 6). ${ }^{24}$

Dengan demikian, peringatan Sunan Kalijaga agar berhati-hati di malam hari itu ada dua hal yang disampaikannya.Pertama, pada saat itu memang kejahatan sering terjadi pada malam hari. Kedua, ia sesungguhnya tengah menafsirkan firman Allah dalam surat al-Falaq dan an-Nas tersebut secara implisit. Hal ini didasarkan pada bentukbentuk kejahatan yang dikemukakannya sangat berkaitan dengan bentuk-bentuk kejahatan dalam kedua surat tersebut. Karena itu, tempat untuk berlindung yang sejati adalah kepada Allah, yang menguasai alam semesta dan seluruh makhluk di dunia ini.

Haruslah dipahami sebagai kiasan, adapun filosofis yang sesungguhnya itu adalah Sang Sabda Kun ( Sang Guru Sejati atau Tuhan Yang Maha Esa). Dialah yang menjaga malam artinya Sang Guru Sejati trsebut akan membawa segala kepastian (takdir) manusia dan yang memiliki daya kuasa yang demikian besar itu. Maka sama dengan orang yang sudah menguasai ilmu, bila waktu 
M. SAKDULLAH: Kidung Rumeksa Ing Wengi

malam selalu berdo'a menunggu ilham apa yang harus dilakukannya setiap harinya, dapat dijadikan pedoman tekad, sehingga pada siang harinya tingga nasibnya, dengan mawas dan sadar diri. Bila tujuannya tadi dapat terbiasa dengan Sang Sabda Kun maka tentu juga memiliki daya kekuasaan seperti yang dijelaskan dalam Kidung Rumeksa Ing Wengi. ${ }^{25}$

\section{Tentang manusia}

Bukan hanya filsafat barat atau alam pikiran India yang kaya dengan telaah kehidupan diri manusia. Sunan Kalijaga pun mengajarkan jati diri manusia kepada masyarakat. Seperti juga pada do'a ajaran tentang filsafat kehidupan yang dituangkan dalam Kidung Rumeksa Ing Wengi. Jika filsafat lebih menitik beratkan pada wacana intelektual, tidak demikian halnya dengan ajaran Kidung Rumeksa Ing Wengi Sunan Kalijaga, yaitu lebih difokuskan kehidupan nyata (menjadi manusia yang waspada). ${ }^{26}$

Sunan Kalijaga mengajak untuk memahami perjalanan hidup dan posisi seseorang dalam menghadapi hidup ini, agar bisa menerima tugas atau kodrat yang telah disetujui dengan suka rela/ mengemban tugas dengan legawa (hati yang lapang). Dari mana dan siapa diri yang sebenarnya, adalah merupakan pertanyaan sejak ribuan tahun lalu yang oleh para ahli pikir dan mistikus mengajukan pertanyaan tentang hal ini. Lebih dari dua ribu tahun yang lalu para ahli pikir dari tanah Yunani beranggapan bahwa manusia itu adalah hewan yang berakal (animal rasionale). Dengan demikian, hakikat jiwa adalah kesadaran atau rasio yang terperangkap badan jasmani. Keadaan ini mendorong seorang filosof barat yang bernama Arthur Schopenhauer (1788-1868) memunculkan gagasan atau esensi hakikat manusia. Menurutnya, "Manusia lahir dari kehendak buta". ${ }^{27}$

Dengan pandangan tersebut diatas manusia sama dengan menerima nasib secara pasif total. Seolah-olah kehadiran manusia di alam ini hanya karena kecelakaan sejarah. Seakan-akan manusia 
hadir karena paksaan dari luar dirinya. Enak dan tidak enak, bahagia dan menderita bukan karena usaha manusia melainkan takdir yang menimpa. Lain halnya dengan keterangan Sunan Kalijaga dalam Kidung Rumeksa Ing Wengi, menjelaskan bahwa:

Songing landak guwaning wong lemah miring

Myang pakiponing merak

Liang landak jadilah gua untuk orang berlaku jahat

Dan tempat merak bermandi pasir.28

Potongan bait di atas adalah merupakan makna kiasan yang ada dalam kidung Rumeksa Ing Wengi. Songing landak guwaning wong lemah miring, myang pakiponing merak. R.Wiryapanitra menjelaskan bahwa makna filosofi sebenarnya adalah asal-usul kejadian manusia. Sebagai perantaranya adalah laki-laki dan perempuan (bapak dan ibu). Adapun keterangan dari bapak ibu terlebur dalam perpaduan kama (persetubuhan dalam bentuk mani/sperma, madi/ovum, wadi/rasa malu pada laki-laki dan maningkem/rasa malu pada perempuan). Di situlah Sang Maha Suci menciptakan makhluk.

\section{Hubungan Manusia dengan Tuhan}

Dalam kidung Rumeksa Ing Wengi ini menunjukkan tentang teologis yang ketiga yaitu hubungan manusia dengan tuhan, hal tersebut tercermin pada potongan bait ke delapan yang berbunyi sebagai berikut:

Lan den sabar sukur ing Widhi

Insya Allah tinekanan

Sakarsa nureku ${ }^{29}$

Seperti dijelaskan di atas yaitu setiap perbuatan ditampakkan dengan sikap sabar, syukur dan pasrah kepada Allah, apabila ini dilakukan dengan sungguh-sungguh dapat dikabulkan oleh Allah, dapat tercapai apa yang dicita-citakan. Secara implisit kidung ini mengajak untuk menguatkan tauhid seseorang kepada Tuhan 
M. SAKDULLAH: Kidung Rumeksa Ing Wengi

(Allah), karena sangat tidak mungkin seseorang syukur serta pasrah kepada sesuatu yang tidak ia percayai.

Seperti apa yang telah dikemukakan pada bab sebelumnya, yakni kualitas keyakinan penuh terhadap Allah, mengharap ampunan dan kemuliaan dari-Nya bisa meningkatkan jiwa orang beriman kepada Allah itu sampai pada tingkat sabar, teguh dan tawakkal kepada-Nya, dimana keteguhan hatinya bisa diibaratkan sebagai batu yang tersimpan di dalam rusuknya. Tidak ada satupun musibah, penderitaan, ancaman dan kesengsaraan duniawi yang mampu menggeser kedua kakinya, sehingga ia bersedia mengendorkan tali kesadaran yang mengikat ert keteguhan dirinya itu.

Kekuatan sabar, tawakkal, dan istiqomah seperti ini merupakan kekuatan yang jauh di atas kekuasaan manusia, yang dengan itu para Rasul ataupun Nabi mampu menghadapi kesulitan dan penderitaan duniawi, serta mampu menggempur kekuasaan dan umatnya yang sewenang-wenang tanpa mempergunakan sarana fisik ketika menaklukkannya.

Jadi hanya memohon perlindungan kepada Allah, karena Dia yang menetapkan dan mengatur hukum-hukum alam, yang menjadikannya muncul di tengah kegelapan malam. Karena biasanya kejahatan atau kesulitan muncul di malam hari atau direncanakan dalam keadaan gelap, baik kejahatan itu dari manusia, binatang dan sebagainya. Jadi dengan menyakini bahwa Allah adalah yang mampu membelah kegelapan malam dengan terangnya pagi seseorang akan yakin pula bahwa Allah juga mampu menyingkirkan kejahatan dan kesulitan baik kapan dan dimanapun akan muncul pertolongan untuk menyingkirkan kesulitan. ${ }^{30}$

Memang boleh saja seseorang meminta bantuan kepada selain Allah, tetapipada saat yang sama ia harus menyadari bahwa pada hakikatnya pihak yang dimintai bantuan itu hanyalah sebagai sebab 
atau sarana yang diciptakan Allah untuk membantu atau melindunginya.

perumpamaan orang-orang yang mengambil perlindungan kepada selain Allah adalah bagaikan laba-laba yang membuat rumah. Sesungguhnya serapuh-rapuh rumah adalah rumah labalaba kalau mereka mengetahui(QS. al-'Ankabūt [29]: 41).

\section{Penutup}

Kidung Rumeksa Ing Wengi merupakan sebuah karya sastra yang berupa simbol verbal, yang digunakan sebagai media pendidikan dan juga dakwah Sunan Kalijaga saat itu.Kidung tersebut memiliki kandungan isi yang bermakna filosofis yang sangat dalam dan memuat unsur-unsur teologis Islam serta mencakup beberapa aspek kehidupan manusia dan masih relevan sampai sekarang. Adapun unsur-unsur teologis yang terkandung dalam Kidung tersebut mencakup tentang Tuhan, manusia, dan hubungan manusia dengan Tuhan.Semua unsur teologis tersebut dikemas oleh Sunan Kalijaga dengan sangat puitis dan dianggap sakral oleh masyarakat Jawa.

\section{Catatan Akhir}

${ }^{1}$ Lihat: M. Bambang Pranowo, Memahami Islam Jawa, Jakarta: Pustaka Alvabet, 2009.

${ }^{2}$ M. Darori Amin (ed.), Islam dan Kebudayaan Jawa, Yogyakarta: Gamamedia, 2000, h.119-120.

${ }^{3}$ Abdul Mu'in DZ, "Mempertahankan Keragaman Budaya", Tashwirul Afkar: Jurnal Refleksi Pemikiran Keagamaan dan Kebudayaan, edisi No, 14, 2003, h. 4-5.

${ }^{4}$ Ibid., h. 5.

5Solichin Salam, Sekitar Walisongo, Kudus: Menara Kudus, 1960, h. 42 .

${ }^{6}$ Lihat: Clifford Geertz, Islam Observed, Chicago: The University of Chicago Press, 1975, h. 25-29.

TEOLOGIA, VOLUME 25, NOMOR 2, JULI-DESEMBER 2014 
${ }^{7}$ Agus Sunyoto, Wali Songo: Rekonstruksi Sejarah yang Disingkirkan, Tangerang: Transpustaka, 2011, h. 140.

${ }^{8}$ Hasanu Simon, Misteri Syekh Siti Jenar: Peran Walisongo Dalam Mengislamkan Tanah Jawa, Yogyakarta: Pustaka Pelajar, 2006, h. 285.

${ }^{9}$ Agus Sunyoto, Wali Songo, h. 140.

10Ibid.

11Ibid., h. 144.

12WidjiSaksono, Mengislamkan Tanah Jawa: Telaah atas Metode Dakwah Walisongo. Bandung: Mizan, 1995, h. 103.

13Ibid., h. 168.

${ }^{14}$ Hasanu Simon, Misteri Syekh Siti Jenar, h. 337-355.

${ }^{15}$ Achmad Chodjim, Mistik dan Ma'rifat Sunan Kalijaga, Jakarta: Serambi Ilmu Semesta, 2003, h. 16.

16 Ibid.

${ }^{17}$ Purwadi, Dakwah Sunan Kalijaga: Penyebaran Agama Islam di Jawa Berbasis Kultural, Yogyakarta: Pustaka Pelajar, 2004, h. 250-256.

${ }^{18}$ Purwadi, Sejarah Sunan Kalijaga: Sintesis Ajaran Wali Sangavs Syekh Siti Jenar, Yogyakarta: Persada, 2003, h. 191-192.

${ }^{19}$ Lihat: Fauzan Saleh, Teologi Pembaharuan: Pergeseran Wacana Islam Sunni di Indonesia Abad XX, Jakarta: Serambi, 2004.

${ }^{20}$ Dalam Serat Sabdatama, R. Ngabehi Ranggawarsita tergerak untuk memberikan pitutur dalam menyikapi "Jaman Kalabendu"; (Kala: Jaman, masa; Bendu: marah; kalau dikatakan "antuk bebenduning Pangeran", artinya mendapatkan amarah atau hukuman dari Allah. Mengapa Tuhan marah? Tentunya karena perbuatan manusia di dunia sudah melampaui batas, terlalu banyak melanggar hukum-hukum Allah).Dalam "Sarine Basa Jawa", Padmasukatja (1967) disebutkan "Kalabendu" sebagai jaman dimana kesusilaan manusia sudah rusak. Ada pengaruh "Bathara Kala disitu".

21Purwadi, Dakwah Sunan Kalijaga, h. 256.

${ }^{22}$ R. Wiryapanira, Serat Kidungan Kawedhar, Jakarta: Depdikbud, 1979, h. 9.

${ }^{23}$ M. Quraish Shihab, Tafsir al-Qur'an al-Karim: Tafsir atas Suratsurat Pendek Berdasarkan Urutan Turunnya Wahyu,Bandung: Pustaka Hidayah, 1997, h. 691.

${ }^{24}$ Ibid.

${ }^{25}$ R. Wiryapanira, Serat Kidungan Kawedhar, h. 9-10.

${ }^{26}$ Achmad Chodjim, Mistik dan Makrifat, h. 73. 
27Zainal Abidin, Filsafat Manusia: Memahami Manusia Dalam Filsafat, Bandung: Remaja Rosdakarya, 2000, h. 156.

${ }^{28}$ R. Wiryapanira, Serat Kidungan Kawedhar, h. 9.

29Ibid., h. 22.

30Muhammad Quraish Shihab, Tafsir al-Qur'an al-Karim, h. 682. 


\section{DAFTAR PUSTAKA}

Abidin, Zainal, Filsafat Manusia: Memahami Manusia Dalam Filsafat, Bandung: Remaja Rosdakarya, 2000.

Amin, M. Darori (ed.), Islam dan Kebudayaan Jawa, Yogyakarta: Gamamedia, 2000.

Chodjim, Achmad, Mistik dan Ma'rifat Sunan Kalijaga, Jakarta: Serambi Ilmu Semesta, 2003.

Mu'in DZ, Abdul, "Mempertahankan Keragaman Budaya”, Tashwirul Afkar: Jurnal Refleksi Pemikiran Keagamaan dan Kebudayaan, edisi No, 14, 2003.

Nasution, M. Yunan, Islam dan Problema Kemasyarakatan, Jakarta: Bulan Bintang, 1988.

Purwadi, Dakwah Sunan Kalijaga: Penyebaran Agama Islam di Jawa Berbasis Kultural, Yogyakarta: Pustaka Pelajar, 2004.

Salam, Solichin, Sekitar Walisongo, Kudus: Menara Kudus, 1960.

Shihab, Muhammad Quraish, Tafsir al-Qur'an al-Karim atas SuratSurat Pendek Berdasarkan Urutan Turunnya Wahyu, Bandung: Pustaka Hidayah, 1999.

Wiryapanira, R., Serat Kidungan Kawedhar, Jakarta: Depdikbud, 1979.

Zuharini, Filsafat Pendidikan Islam, Jakarta: Bumi Aksara. 